\title{
Mental Health Status of Nepalese Students during Novel Coronavirus Disease (nCOVID-19) Pandemic
}

Isha Karmacharya ${ }^{1 *}$, Shital Shrestha ${ }^{1}$, Sachina Paudel ${ }^{2}$, Laxmi Adhikari ${ }^{1}$, Kshitiz Bhujel $^{3}$, Karuna Laxmi Shakya ${ }^{1}$

\section{Author Info:}

1Public Health Department, CiST College, New Baneshwor, Kathmandu, 44602, Nepal

${ }^{2}$ Public Health Officer, Urban Health Promotion Centre, Bharatpur Metropolitan City, Government of Nepal Author's Affiliation

${ }^{3}$ Annapurna Neurological Institute \& Allied Sciences, Kathmandu, 44602, Nepal

\section{Corresponding Author:}

Isha Karmacharya, CiST College, Kathmandu, 44602, Nepal;

Email/Contact: ishakarmacharya@gmail.com

\begin{abstract}
Background: Since the wave of COVID-19, human life has highly been affected due to government endorsement of containment measures to control the disease. Education system has been held back and students are one of those who are greatly affected. Thus, this study attempts to find out the mental health status of Nepalese students during novel coronavirus Disease (nCOVID-19) pandemic.

Methodology: A web-based cross sectional descriptive study was conducted from 9 May to 29 May 2020 among 517 students of Nepal aged 18 years and above. A structured questionnaire was adopted from DASS-21. The responses on the online questionnaire had transferred into Microsoft Excel and the data analysis was conducted in IBM SPSS Statistics for Windows Version 21.0. Descriptive frequency, percent and mean were calculated, and chi-square test was performed for bivariate analysis.

Results: The mean age of the study participants was $21.4 \pm 2.7$ years. This study found that majority of the Nepalese students had normal status of depression (69.6\%), anxiety (71.4\%) and stress (71.4\%). Perceived family relationship however, showed statistical significance in all three mental health parameters $(p<0.001)$; depression, anxiety and stress. Depression was found to be comparatively more in females $(p<0.05)$, and those who held Bachelor's and above degrees have shown presence of anxiety $(p<0.05)$ and stress $(p<0.05)$ relatively than those holding below degrees.

Conclusion: Majority of the Nepalese students had normal status of depression, anxiety and stress during the nationwide lockdown. Perceived family relationship however, showed statistical significance in all three mental health parameters. This is a wake-up call for education system to focus on socio-emotional skills - empathy and solidarity in easing this pandemic crisis confronted by young learners and their families.
\end{abstract}

Keywords: Anxiety, Depression, DAS-21, Mental Health, Stress, Students, Youth

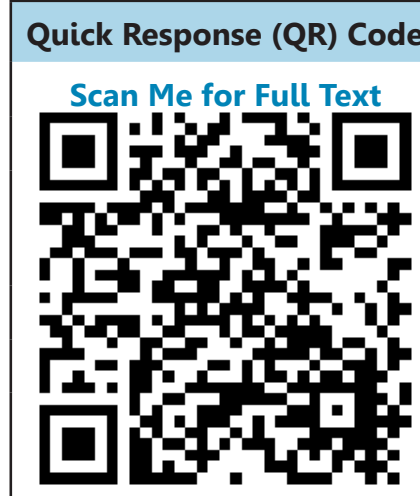

View PDF

\section{Article Info}

Received: 5 September 2020; Accepted: 27 October 2020; Published Online: 28 October 2020 How to cite this article in Vancouver Style?

Karmacharya I, Shrestha S, Paudel S, Adhikari L, Bhujel K, Shakya KL. Mental Health Status of Nepalese Students during Novel Coronavirus Disease (nCOVID-19) Pandemic. Europasian J Med Sci. 2020; 2(COVID-19 Special Issue): 13-21. https://doi.org/10.46405/ejms.v2i2.172

\section{Disclaimer}

Conflict of Interest: None Declared;

Source of Support: Nil

Copyright: ( $) 2020$ by author(s). This is an open access article distributed under the terms of the Creative Commons Attribution International License 4.0 (http://creativecommons.org/licenses/ by/4.0/) which permits unrestricted use, distribution, and reproduction in any medium, provided the original work is properly cited.

\section{Publisher's Note}

The Europasian Journal of Medical Sciences (EJMS) (www.europasianjournals.org) is an official Journal of Nirvana Psychosocial Care Center \& Ressearch Institute (www.nirvanapscc.com). The Journal as well as publisher remain neutral with regards to any jurisdictional claims in any published articles, its contents and the institutional affiliations of the authors. 


\section{INTRODUCTION}

The World Health Organization declared COVID-19 as an international public health emergency on January 30, 2020 and later declared as global pandemic on March 11, 2020 which was $1^{\text {st }}$ originated in Wuhan, China on the late December, 2019. ' China started imposing lockdown from $23^{\text {rd }}$ January, later followed by different countries in the world. The Government of Nepal also announced on May 17 an extension to the nationwide lockdown as of 2359 hours which had affected the life of many people directly or indirectly. This pandemic has exacerbated global atmosphere of stress, anxiety, depression, social isolation, hoarding of food items, infodemics, academic and financial burden. ${ }^{1-5}$

The quality of life is ensured not only by the maintenance of physical health rather it requires wellbeing of all three components including mental and social wellbeing. ${ }^{6}$ Mental health of students is one of the burning issues of the $21^{\text {st }}$ century. Student life which is also considered to be one of the mentally difficult stages of life, and is the most crucial time for a person to determine a sustainable future along with a quality of life. ${ }^{7}$ The year 2020, has turned the year into a panic frenzy due to rapid spread of COVID-19. Students are one of those who are greatly affected due to this pandemic. ${ }^{8}$

Around 181 countries in the world have held back their education system till $1^{\text {st }}$ May 2020 leading $73.5 \%$ (1.3 billion young people) of enrolled learners worldwide out of education and 8.8 million affected learners in Nepal. ${ }^{9}$ Many countries are cancelling or postponing their university examination leaving students to lock down in their own rooms or homes which has further led to lack of access to resources they previously used to have. Most of the time schools and colleges regular routines become the coping mechanism for the younger people with mental issues which has totally been constrained during this pandemic. A poll by the student counseling group Hok Yau Club in March, 2020, among 757 candidates surveyed, over $20 \%$ said their stress levels were at a maximum 10 out of 10 , even before the postponement was announced. Some were experiencing sleep problems, loss of appetite and some were worried about they may contracted with the virus restricting them from appearing in the examination further mentioning "Staying healthy has become another stressor". ${ }^{4}$

A cross-sectional study on Mental Health Status was conducted among the South Indian pharmacy students during COVID-19 pandemic which concluded that $26 \%$ of respondents reported severe to extremely severe depressive symptoms; $31.5 \%$ of respondents reported severe to extremely severe anxiety symptoms, and $19 \%$ reported severe to extremely severe stress levels suggesting need of conducting more such studies which further helps to prepare appropriate psychological interventions to improve mental health among the young students during the pandemic. ${ }^{10}$

In reality common mental disorders such as anxiety, depression and eating disorders are extremely common among students which are usually considered as huge taboos in the society preventing them from admitting the condition. ${ }^{7}$ In fact, a mental health research conducted by the National Alliance on Mental IIIness (NAMI), one in four students has a diagnosable mental illness ranging from mild depression and anxiety to serious disorders like Schizophrenia, bipolar disorder, etc. ${ }^{11,} 12$ In the context of Nepal, there are students who are facing financial burden and are fighting for survival which has led them to great distress along with the inability to access the resources like internet, reading materials, road, etc. ${ }^{13}$ Infodemics during this pandemic has also caused great panic among students along with their families and peers. ${ }^{13,14}$

Although schools and colleges are coming up with the alternatives to carry out the academic session through online platforms, it is still a great concern for those who do not have the privilege of accessing such services. Most days are also usually spent freely at home, due to which many students are also showing signs of anxiety due to not having the freedom as before. Although these are the most common scenarios, a greater fear of acquiring the illness and being powerless to deal with is also increasing with every passing day. ${ }^{11}$ Mental health disorders have often time led to death of many young students due to which it is essential to actively address this problem as soon as possible. ${ }^{7}$ Thus, this study attempts to find out the mental health status of Nepalese students during novel coronavirus Disease (nCOVID-19) pandemic.

\section{MATERIALS AND METHODS}

\section{Study Design, Participants}

A web-based cross sectional descriptive study was conducted from 9 May to 29 May 2020 among students of Nepal aged 18 years and above. Unrestricted self-selected (convenient nonprobability) sampling method adopted to generate 
a heterogeneous sample. ${ }^{15}$

\section{Survey Instruments and Variables}

The online survey questionnaire was organized into two different sections: (a) Socio-demographic information, (b) Mental health of COVID-19.

\section{a) Socio-demographic Information}

A questionnaire was developed to obtain sociodemographic information. It included information on the participant's age, sex, ethnicity, education level, and place of current residence. Participant's education status started from higher secondary level and above. The family characteristics were participants currently living with, family type, economic status, and participants' perception on relationship with their family.

\section{b) Mental Health Status}

A structured questionnaire was adopted from DASS-21 with necessary modifications as according to Nepalese context to assess the mental health status. It was assessed by using The Depression, Anxiety and Stress Scale - 21. Items (DASS-21) which is a set of three self-report scales designed to measure the emotional states of depression, anxiety and stress. ${ }^{16}$ The rating scales ranged from 0-3. The recommended cut-off scores for conventional severity labels (normal, moderate, severe) are as follows: Scores on the DASS-21 would need to be multiplied by 2 to calculate the final score. The score shall be further categorized as normal, mild, moderate, severe and extremely severe; as follows:

\begin{tabular}{llll}
\multicolumn{2}{l}{ Data Collection } & & \\
\hline Stage & Depression & Anxiety & Stress \\
\hline Normal & $0-9$ & $0-7$ & $0-14$ \\
\hline Mild & $10-13$ & $8-9$ & $15-18$ \\
\hline Moderate & $14-20$ & $10-14$ & $19-25$ \\
\hline Severe & $26-33$ & $15-19$ & $21-27$ \\
\hline $\begin{array}{l}\text { Extremely } \\
\text { Severe }\end{array}$ & $28+$ & $20+$ & $34+$ \\
& & &
\end{tabular}

The data was collected through a set of questionnaire which was shared in the survey links in different social media such as Facebook, Twitter, Linkedln, and Messenger. The development and reporting of the survey followed the Checklist for Reporting Results of Internet E-survey (CHERRIES) ${ }^{17}$ guidelines. CHERRIES items are valid for surveys administered via e-mail, the checklist focuses on web-based surveys. ${ }^{17}$

\section{Statistical Analysis}

The responses on the online questionnaire had transferred into Microsoft Excel and the data analysis was conducted in IBM SPSS Statistics for Windows Version 21.0 (IBM Corp. Armonk, NY, USA). Simple descriptive statistics such as percentage, frequency and mean were used to describe each response to the questionnaire. Pearson's chi-square $(\chi 2)$ or Fisher's exact tests and $t$-test were used respectively to observe the differences between the groups. $\mathrm{P}$-value $<0.05$ was considered as statistically significant result.

\section{Ethical Considerations}

The Institutional Review Committee at Central Institute of Science and Technology, affiliated with Pokhara University, Nepal, approved the study. The informed consent was taken from every participant before the commencement of the survey. The anonymity and confidentiality of the participants was maintained throughout the study. The participation of the respondents in the survey was voluntary, and no any kind of incentives was provided to them.

\section{RESULTS}

A total of 517 respondents voluntarily involved in the study, their age ranged from minimum 18 vears to maximum 35 years, with an average of 21.4

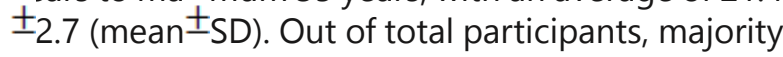
were female $378(73.1 \%)$ and male 139 (26.9\%). $348(67.3 \%)$ came from privileged ethnic group out of the total. Majority $93.8 \%$ held bachelor's and above degree. More number of study participants resided in Bagmati Province whereas, 94.8\% of them lived with their family. Majority of them 387 (74.9\%) belonged to nuclear family and on the basis of perceived economic status; $139(26.9 \%)$, $345(66.7 \%)$, 33(6.4\%) belonged to wealthy, medium and medium low status respectively. Majority of the participants (90.3\%) perceived good family relationship. Minority of them (3.5\%) has family returning from abroad in recent time. This study has focused primarily on three mental health parameters (depression, anxiety and stress) in order to find out the mental health status of Nepalese students during novel coronavirus Disease (nCOVID-19) pandemic.

\section{Depression by Socio demographic and Family Characteristics and its correlates}

Majority of the students were found to be in normal status (69.6\%), followed by mild and moderate depression (10.8\%), severe (4.1\%) and extremely 
Table 1. Depression by Socio-demographic and Family Characteristics

\begin{tabular}{|c|c|c|c|c|c|c|c|}
\hline \multirow{2}{*}{ Characteristics } & \multirow[b]{2}{*}{ Total } & \multicolumn{6}{|c|}{ Depression, $\mathbf{n}(\%)$ or mean ${ }^{ \pm}$standard deviation } \\
\hline & & Normal & Mild & Moderate & Severe & $\begin{array}{l}\text { Extremely } \\
\text { Severe }\end{array}$ & p-value \\
\hline Age-group(years) & $21.4 \pm 2.7$ & $21.5 \pm 2.6$ & $21.3 \pm 3.2$ & $20.8 \pm 2.2$ & $21.3 \pm 3.4$ & $22.3 \pm 2.9$ & $0.194^{b}$ \\
\hline \multicolumn{8}{|c|}{$\operatorname{Min}^{m}=18$ years; Max $^{m}=35$ years } \\
\hline Gender & & & & & & & $0.013^{* a}$ \\
\hline Male & $139(26.9)$ & $96(69.1)$ & $9(6.5)$ & $17(12.2)$ & $4(2.9)$ & $13(9.4)$ & \\
\hline Female & $378(73.1)$ & $264(69.8)$ & $47(12.4)$ & $39(10.3)$ & $17(4.5)$ & $11(2.9)$ & \\
\hline Ethnicity & & & & & & & 0.297 \\
\hline Privileged & $348(67.3)$ & $243(69.8)$ & $43(12.4)$ & $36(10.3)$ & $11(3.2)$ & $15(4.3)$ & \\
\hline Underprivileged & $169(32.7)$ & $117(69.2)$ & $13(7.7)$ & $20(11.8)$ & $10(5.9)$ & $9(5.3)$ & \\
\hline Education & & & & & & & $0.408^{\mathrm{a}}$ \\
\hline $\begin{array}{l}\text { Bachelor's and } \\
\text { above }\end{array}$ & $485(93.8)$ & $338(69.7)$ & $51(10.5)$ & $51(10.5)$ & $21(4.3)$ & $24(4.9)$ & \\
\hline Higher Secondary & $32(6.2)$ & $22(68.8)$ & $5(15.6)$ & $5(15.6)$ & $0(0.0)$ & $0(0.0)$ & \\
\hline $\begin{array}{l}\text { Province of current } \\
\text { residence }\end{array}$ & & & & & & & 0.883 \\
\hline Bagmati Province & $278(53.8)$ & $191(68.7)$ & $29(10.4)$ & $32(11.5)$ & $11(4.0)$ & $15(5.4)$ & \\
\hline Other Provinces" & 239 (46.2) & $169(70.7)$ & $27(11.3)$ & $24(10.0)$ & $10(4.2)$ & $9(3.8)$ & \\
\hline With whom living & & & & & & & $0.619^{a}$ \\
\hline With Family & $490(94.8)$ & $342(69.8)$ & $53(10.8) 4 \%$ & $54(11.0)$ & $19(3.9)$ & $22(4.5)$ & \\
\hline Other than Family & $27(5.2)$ & $18(66.7)$ & $3(11.1)$ & $2(7.4)$ & $2(7.4)$ & $2(7.4)$ & \\
\hline Family Type & & & & & & & 0.925 \\
\hline Nuclear & $387(74.9)$ & $270(69.8)$ & $44(11.4)$ & $40(10.3)$ & $15(3.9)$ & $18(4.7)$ & \\
\hline Joint/Extended & $130(25.1)$ & $90(69.2)$ & $12(9.2)$ & $16(12.3)$ & $6(4.6)$ & $694.6)$ & \\
\hline $\begin{array}{l}\text { Perceived Economic } \\
\text { Status }\end{array}$ & & & & & & & $0.122^{\mathrm{a}}$ \\
\hline $\begin{array}{l}\text { Wealthy } \\
\text { Medium } \\
\text { Medium Low }\end{array}$ & $\begin{array}{l}139(26.9) \\
345(66.7) \\
33(6.4)\end{array}$ & $\begin{array}{l}107(77.0) \\
230(66.7) \\
23(69.7)\end{array}$ & $\begin{array}{l}8(5.8) \\
45(13.0) \\
3(9.1)\end{array}$ & $\begin{array}{l}16(11.5) \\
38(11.0) \\
2(6.1)\end{array}$ & $\begin{array}{l}4(2.9) \\
16(4.6) \\
1(3.0)\end{array}$ & $\begin{array}{l}4(2.9) \\
16(4.6) \\
4(12.1)\end{array}$ & \\
\hline $\begin{array}{l}\text { Perceived Family } \\
\text { Relationship }\end{array}$ & & & & & & & $<0.001 * * a$ \\
\hline Good & $467(90.3)$ & $344(73.7)$ & $53(11.3)$ & $48(10.3)$ & $15(3.2)$ & $7(1.5)$ & \\
\hline Satisfactory & $38(7.4)$ & $16(42.1)$ & $3(7.9)$ & $8(21.1)$ & $5(13.2)$ & $6(15.8)$ & \\
\hline Poor & $12(2.3)$ & $0(0.0)$ & $0(0.0)$ & $0(0.0)$ & $1(8.3)$ & $11(91.7)$ & \\
\hline Family returned from & & & & & & & $0.3833^{a}$ \\
\hline $\begin{array}{l}\text { Yes } \\
\text { Yes }\end{array}$ & $18(3.5)$ & $16(88.9)$ & $1(5.6)$ & $0(0.0)$ & $1(5.6)$ & $0(0.0)$ & \\
\hline No & $499(96.5)$ & 344 (68.9) & $55(11.0)$ & $56(11.2)$ & $20(4.0)$ & $24(4.8)$ & \\
\hline
\end{tabular}

\# other provinces are Province 1, Province 2, Gandaki Province, Lumbini Province, Karnali Province and Sudur Paschhim Province; *significance at $p<0.05 ;{ }^{*}$ significance at $p<0.001$

ap-value from Fisher's exact test;

${ }^{b} p$-value from One-way ANOVA test; all others are from Chi-square test.

severe depression (4.6\%). The gender of the respondents showed statistical significance with depression with $p$-value less than 0.05 ( $p$-value $=$ 0.013), while perceived family relationship of the respondents showed statistical significance with $p$-value less than 0.001 . None of the other sociodemographic and family characteristics were found to be associated with depression.

\section{Anxiety by Socio-demographic and Family Characteristics and its correlates}

Majority of the students were found to be in normal status (71.4\%); mild anxiety (4.8\%), moderate (14.3\%), severe (3.5\%) and extremely severe anxiety (6.0\%). The education level of the respondents showed statistical significance with anxiety with $p$-value less than 0.05 ( $p$-value $=0.015)$, while perceived family relationship of the respondents showed statistical significance with anxiety with $\mathrm{p}$-value less than 0.001 . None of the other sociodemographic and family characteristics were found to be associated with anxiety. 
Table 2. Anxiety by Socio-demographic and Family Characteristics

\begin{tabular}{|c|c|c|c|c|c|c|c|}
\hline \multirow[b]{2}{*}{ Characteristics } & \multirow[b]{2}{*}{ Total } & \multicolumn{6}{|c|}{ Anxiety,n (\%) or mean ${ }^{ \pm}$standard deviation } \\
\hline & & Normal & Mild & Moderate & Severe & $\begin{array}{r}\text { Extremely } \\
\text { Severe }\end{array}$ & p-value \\
\hline Age-group(years) & $21.4 \pm 2.7$ & $21.4 \pm 2.7$ & $20.7 \pm 1.6$ & $21.3 \pm 2.5$ & $21.1 \pm 2.9$ & $22.6 \pm 3.5$ & $0.067^{b}$ \\
\hline Gender & & & & & & & $0.447^{\mathrm{a}}$ \\
\hline Male & $139(26.9)$ & $93(66.9)$ & $8(5.8)$ & $22(15.8)$ & $4(2.9)$ & $12(8.6)$ & \\
\hline Female & $378(73.1)$ & $276(73.0)$ & $17(4.5)$ & $52(13.8)$ & $14(3.7)$ & $19(5.0)$ & \\
\hline Ethnicity & & & & & & & 0.845 \\
\hline Privileged & $348(67.3)$ & $245(70.4)$ & $19(5.5)$ & $51(14.7)$ & $13(3.7)$ & $20(5.7)$ & \\
\hline Underprivileged & 169 (32.7) & $124(73.4)$ & $6(3.6)$ & $23(13.6)$ & $5(3.0)$ & $11(6.5)$ & \\
\hline Education & & & & & & & $0.015^{* a}$ \\
\hline $\begin{array}{l}\text { Bachelor's and } \\
\text { above }\end{array}$ & $485(93.8)$ & $343(70.7)$ & $24(4.9)$ & $73(15.1)$ & $14(2.9)$ & $31(6.4)$ & \\
\hline Higher Secondary & $32(6.2)$ & $26(81.3)$ & $1(3.1)$ & $1(3.1)$ & $4(12.5)$ & $0(0.0)$ & \\
\hline $\begin{array}{l}\text { Province of current } \\
\text { residence }\end{array}$ & & & & & & & 0.349 \\
\hline Bagmati Province & $278(53.8)$ & $188(67.6)$ & $15(5.4)$ & $44(15.8)$ & $12(4.3)$ & $19(6.8)$ & \\
\hline Other Provinces ${ }^{\#}$ & $239(46.2)$ & $181(75.7)$ & $10(4.2)$ & $30(12.6)$ & $6(2.5)$ & $12(5.0)$ & \\
\hline With whom living & & & & & & & $0.499^{a}$ \\
\hline With Family & $490(94.8)$ & $349(71.2)$ & $25(5.1)$ & $71(14.5)$ & $16(3.3)$ & $29(5.9)$ & \\
\hline Other than Family & $27(5.2)$ & $20(74.1)$ & $0(0.0)$ & $3(11.1)$ & $2(7.4)$ & $2(7.4)$ & \\
\hline Family Type & & & & & & & $0.412^{\mathrm{a}}$ \\
\hline Nuclear & $387(74.9)$ & $284(73.4)$ & $17(4.4)$ & $50(12.9)$ & $13(3.4)$ & $23(5.9)$ & \\
\hline Joint/Extended & $130(25.1)$ & $85(65.4)$ & $8(6.2)$ & $24(18.5)$ & $5(3.8)$ & $8(6.2)$ & \\
\hline $\begin{array}{l}\text { Perceived Economic } \\
\text { Status }\end{array}$ & & & & & & & $0.229^{a}$ \\
\hline Wealthy & 139 (26.9) & $108(77.7)$ & $4(2.9)$ & $15(10.8)$ & $5(3.6)$ & $7(5.0)$ & \\
\hline Medium & $345(66.7)$ & $238(69.0)$ & $19(5.5)$ & $57(16.5)$ & $11(3.2)$ & $20(5.8)$ & \\
\hline Medium Low & $33(6.4)$ & $23(69.7)$ & $2(6.1)$ & $2(6.1)$ & $2(6.1)$ & $4(12.1)$ & \\
\hline Perceived Family & & & & & & & $<0.001^{* * a}$ \\
\hline $\begin{array}{l}\text { Relationship } \\
\text { Good }\end{array}$ & $467(90.3)$ & $353(75.6)$ & $23(4.9)$ & 61 (13.1) & $16(3.4)$ & $14(3.0)$ & \\
\hline Satisfactory & $38(7.4)$ & $16(42.1)$ & $2(5.3)$ & $11(28.9)$ & $1(2.6)$ & $8(21.1)$ & \\
\hline Poor & $12(2.3)$ & $0(0.0)$ & $0(0.0)$ & $2(16.7)$ & $1(8.3)$ & $9(75.0)$ & \\
\hline $\begin{array}{l}\text { Family returned from } \\
\text { abroad }\end{array}$ & & & & & & & $0.391^{a}$ \\
\hline Yes & $18(3.5)$ & $12(66.7)$ & $2(11.1)$ & $3(16.7)$ & $1(5.6)$ & $0(0.0)$ & \\
\hline No & 499 996.5) & 357 (71.5) & $23(4.6)$ & $71(14.2)$ & $17(3.4)$ & $31(6.2)$ & \\
\hline
\end{tabular}

\section{Stress by Socio-demographic and Family Characteristics and its correlates}

Majority of the students were found to be in normal status $(71.4 \%)$; mild stress $(5.2 \%)$, moderate $(7.7 \%)$, severe (4.4\%) and extremely severe stress (3.3\%). The education level of the respondents showed statistical significance with stress with a $p$-value 0.015 which is less than 0.05 , while perceived family relationship of the respondents showed statistical significance with stress with $p$-value less than 0.001 . None of the other socio-demographic and family characteristics were found to be associated with stress.

\section{DISCUSSION}

The global pandemic of Novel coronavirus disease (nCOVID19) has succeeded to affect every individual's life in some or the other way. Most countries faced nationwide lockdowns, preventing them from travelling and doing daily activities that has not only caused obstacles but directly or indirectly created mental stress among the people.

Previous studies on mental health status among students during COVID-19 are limited. The people of all ages could become vulnerable and develop mental health problems in terms of depression, anxiety and stress due to fear of getting infected, 
Table 3. Stress by Socio-demographic and Family Characteristics

\begin{tabular}{|c|c|c|c|c|c|c|c|}
\hline \multirow[b]{2}{*}{ Characteristics } & \multirow[b]{2}{*}{ Total } & \multicolumn{6}{|c|}{ Stress, n (\%) or mean ${ }^{ \pm}$standard deviation } \\
\hline & & Normal & Mild & Moderate & Severe & $\begin{array}{r}\text { Extremely } \\
\text { Severe }\end{array}$ & p-value \\
\hline Age-group(years) & $21.4 \pm 2.7$ & $21.5^{ \pm} 2.7$ & $20.5^{ \pm} 1.8$ & $20.9 \pm 3.2$ & $21.4 \pm 1.8$ & $22.4 \pm 3.2$ & $0.144^{b}$ \\
\hline Gender & & & & & & & $0.373^{\mathrm{a}}$ \\
\hline Male & $139(26.9)$ & $109(78.4)$ & $4(2.9)$ & $12(8.6)$ & $7(5.0)$ & $7(5.0)$ & \\
\hline Female & $378(73.1)$ & $301(79.6)$ & $23(6.1)$ & $28(7.4)$ & $16(4.2)$ & $10(2.6)$ & \\
\hline Ethnicity & & & & & & & 0.836 \\
\hline Privileged & $348(67.3)$ & 278 (79.9) & $16(4.6)$ & $26(7.5)$ & $17(4.9)$ & $11(3.2)$ & \\
\hline Underprivileged & $169(32.7)$ & $132(78.1)$ & $11(6.5)$ & $14(8.3)$ & $6(3.6)$ & $6(3.6)$ & \\
\hline Education & & & & & & & $0.023^{* a}$ \\
\hline $\begin{array}{l}\text { Bachelor's and } \\
\text { above }\end{array}$ & $485(93.8)$ & $388(80.0)$ & $24(4.9)$ & $33(6.8)$ & $23(4.7)$ & $17(3.5)$ & \\
\hline Higher Secondary & $32(6.2)$ & $22(68.8)$ & $3(9.4)$ & 7 (21.9) & $0(0.0)$ & $0(0.0)$ & \\
\hline $\begin{array}{l}\text { Province of current } \\
\text { residence }\end{array}$ & & & & & & & 0.128 \\
\hline Bagmati Province & $278(53.8)$ & 211 (75.9) & $14(5.0)$ & $28(10.1)$ & $13(4.7)$ & $12(4.3)$ & \\
\hline Other Provinces ${ }^{\#}$ & $239(46.2)$ & $199(83.3)$ & $13(5.4)$ & $12(5.0)$ & $10(4.2)$ & $5(2.1)$ & \\
\hline With whom living & & & & & & & $0.300^{\mathrm{a}}$ \\
\hline With Family & $490(94.8)$ & $388(79.2)$ & $27(5.5)$ & $37(7.6)$ & $23(4.7)$ & $15(3.1)$ & \\
\hline Other than Family & $27(5.2)$ & $22(81.5)$ & $0(0.0)$ & $3(11.1)$ & $0(0.0)$ & $2(7.4)$ & \\
\hline Family Type & & & & & & & $0.773^{a}$ \\
\hline Nuclear & $387(74.9)$ & $309(79.8)$ & $19(4.9)$ & $31(8.0)$ & $15(3.90$ & $13(3.4)$ & \\
\hline Joint/Extended & $130(25.1)$ & $101(77.7)$ & $8(6.2)$ & $9(6.9)$ & $8(6.2)$ & $4(3.1)$ & \\
\hline $\begin{array}{l}\text { Perceived Economic } \\
\text { Status }\end{array}$ & & & & & & & $0.322^{a}$ \\
\hline Wealthy & 139 (26.9) & $114(82.0)$ & $6(4.3)$ & $11(7.9)$ & $2(1.4)$ & $6(4.3)$ & \\
\hline Medium & $345(66.7)$ & $272(78.8)$ & $20(5.8)$ & $25(7.2)$ & $19(5.5)$ & $9(2.6)$ & \\
\hline Medium Low & $33(6.4)$ & $24(72.7)$ & $1(3.0)$ & $4(12.1)$ & $2(6.1)$ & $2(6.1)$ & \\
\hline $\begin{array}{ll}\text { Perceived } & \text { Family } \\
\text { Relationship } & \end{array}$ & & & & & & & $<0.001 * * a$ \\
\hline Good & $467(90.3)$ & $390(83.5)$ & $24(5.1)$ & $37(7.9)$ & $11(2.4)$ & $5(1.1)$ & \\
\hline Satisfactory & $38(7.4)$ & $20(52.6)$ & $3(7.9)$ & $3(7.9)$ & $6(15.8)$ & $6(15.8)$ & \\
\hline Poor & $12(2.3)$ & $0(0.0)$ & $0(0.0)$ & $0(0.0)$ & $6(50.0)$ & $6(50.0)$ & \\
\hline $\begin{array}{l}\text { Family returned from } \\
\text { abroad }\end{array}$ & & & & & & & $0.588^{a}$ \\
\hline Yes & $18(3.5)$ & $16(88.9)$ & $1(5.6)$ & $0(0.0)$ & $0(0.0)$ & $1(5.6)$ & \\
\hline No & 499 996.5) & $394(79.0)$ & $26(5.2)$ & $40(8.0)$ & $23(4.6)$ & $16(3.2)$ & \\
\hline
\end{tabular}

\# other provinces are Province 1, Province 2, Gandaki Province, Province 5, Karnali Province and Sudur Paschhim Province; *significance at $p<0.05 ;{ }^{* *}$ significance at $p<0.001$

ap-value from Fisher's exact test; ${ }^{b} \mathrm{p}$-value from One-way ANOVA test; all others are from Chi-square test.

concerns about protection of the health and wellness of their family and socio-economic effect of lockdown.

This study found optimal mental health status among Nepalese students in early phases of nationwide lockdown. The family relationship, particularly good or satisfactory among the participants was notable. Perceived family relationship however, showed statistical significance in all three mental health parameters; depression, anxiety and stress.

The unexpected yet interesting findings of this study is the levels of depression, anxiety and stress is not extreme despite how the positive cases of COVID-19 has been increasing rapidly and for country like Nepal, it could result even more hazardous. ${ }^{18}$ Depression was found to be comparatively more in females ranging from mild to extremely severe. One of the possible reasons could be how the women are burdened with household chores, increased domestic violence cases; gender based violence cases and for those who work from home during lockdown it is more challenging. Women Rehabilitation Center (WOREC) documented 624 cases of violence against women and girls from 55 districts of Nepal during lockdown. ${ }^{19}$

The respondents who held Bachelor's and above degrees have shown presence of depression, 
anxiety and stress relatively than those holding below degrees. The prolongation of lockdown, uncertainty of board exams in Bachelor and above levels could have played a massive role for this result, as the issue exam of school leaving level and higher secondary level has been sorted by the Government in Nepal ${ }^{18,20}$, yet for the higher degrees are in dilemma. With the fact that matriculation process for further studies and job opportunity has been in depletion, as the country has been facing crisis on job opportunity with number of migrant workers and people from abroad returning back to the country. ${ }^{21}$; it is clear that it has possibly affected Bachelor's and above degree holders in terms of career development and future plans. A longitudinal study done in China has supported this result with stating how prolonged lockdown has several adverse impact on mental health especially aged 12-21.4 years which comprise students affected by school closure, requiring online education, uncertainty of exams and matriculation arrangements. ${ }^{22}$ A news from Aljazeera reported that because of schools being shut down in India to overcome COVID-19 pandemic affecting the students who cannot afford expensive devices with no access to online education, a 14 year old girl from Southern state of Kerala committed suicide on the first day of new school term. ${ }^{23}$

Given that this study was done in the earlier stage of lockdown in the nation which showed more percentage of respondents claiming to have normal state of mental health which could be a possibility that the persistence of their mental health status was not defined and clear. A commentary study done in the USA showed that, among college students, mental health problems not only are common, but they often persist for several years 24 through longitudinal data on 763 students, observed that $60 \%$ of those who had a mental health problem at baseline continued to report at least one mental health problem 2 years later. ${ }^{25}$

A study done in Changzhi medical college, China showed that, the COVID-19-related stressors, which include economic stressors, effects on daily-life, and academic delays, were positively associated with anxiety symptoms of Chinese college students during the epidemic. ${ }^{26}$. In contrast to this study the perceived economic was not associated with mental health status of Nepalese students.

Perceived family relationship however, showed statistical significance in all three mental health parameters; depression, anxiety and stress. The poor family relationship among the participants showed presence of depression, anxiety and stress either in severe or extremely severe forms being it quite notable. Similarly, previous studies suggest that a wide variety of parent and family influences is correlated with youth vulnerability for mental illness, ranging from parental dysfunction to parental cognitive style to family emotional environment. ${ }^{27,28}$

\section{Strengths and Limitations}

Since, the majority of the participants were involved from Bagmati Province of Nepal which locates capital city of the country, gives a limitation for this study as this is a web based survey and it can be seen that $51.15 \%$ Nepalese use internet according to MIS report of Nepal Telecommunication ${ }^{29,30}$ because of which randomization of covering the respondents from whole country could not be done. This study could be a baseline study for those researchers who wish to work further on mental health among students population in Nepal during the pandemic and beyond.

\section{CONCLUSION}

The unexpected yet interesting finding of this study is the levels of depression, anxiety and stress is optimal among the Nepalese students despite how the COVID-19 pandemic is worsening the education system in Nepal. Depression was found to be comparatively more in females ranging from mild to extremely severe. The participants those who held Bachelor's and above degrees have shown presence of anxiety and stress relatively than those holding below degrees. Perceived family relationship however, showed statistical significance in all three mental health parameters. The COVID-19 pandemic has given us a glimpse of how everything can alter in a blink of eye, and likewise, how education can evolve. Thus, this is a wake-up call for education system to focus on socio-emotional skills - empathy and solidarity in easing this pandemic crisis confronted by young learners and their families.

\section{Acknowledgement}

We are grateful to Prof. Naveen Shrestha for insightful discussions to initiate this study. We would also like to thank Ms. Saloni Pandey, Ms. Deepa Ghimire, Ms. Bhawana Kafle and Bandana Dhakal for their assistance and support during the data collection. 


\section{REFERENCES}

1. Mahase E. China coronavirus: WHO declares international emergency as death toll exceeds 200. BMJ. 2020; 368: m408. https://doi.org/10.1136/bmj. m408.

2. Ghebreyesus TA. WHO Director-General's opening remarks at the media briefing on COVID-19-11 March. World Health Organization. 2020; https:// www.who.int/dg/speeches/detail/whodirectorgeneral-s-opening-remarks-at-the-media-briefingoncovid-19-11-march-2020

3. Ho CS, Chee CY and Ho RC. Mental health strategies to combat the psychological impact of COVID-19 beyond paranoia and panic. Ann Acad Med Singapore. 2020; 49(1): 1-3. http://doi.org/10.1136/ bmj.m1211.

4. Lee J. Mental health effects of school closures during COVID-19. The Lancet Child \& Adolescent Health. 2020; 4(6): 421. https://doi.org/10.1016/S23524642(20)30109-7.

5. US Embassy Nepal. COVID-19 information. 2020; https://np.usembassy.gov/covid-19-information/

6. Kessler RC and Üstün TB. The World Mental Health (WMH) Survey Initiative version of the World Health Organization (WHO) Composite International Diagnostic Interview (CIDI). International Journal of Methods in Psychiatric Research. 2004; 13(2): 93121. http://doi.org/10.1002/mpr.168.

7. Pedrelli $P$, Nyer $M$, Yeung $A$, et al. College Students: Mental Health Problems and Treatment Considerations. Acad Psychiatry. 2015; 39(5): 503511. https://doi.org/10.1007/s40596-014-0205-9.

8. Network TL. What Students Are Saying About Living Through a Pandemic. 2020; https://www.nytimes. com/2020/03/26/learning/what-students-aresaying-about-living-through-a-pandemic.html

9. UNESCO. Global Monitoring of School Closures caused by COVID-19. 2020; https://en.unesco.org/ covid19/educationresponse

10. Suryadevara V, Adusumalli C, Adusumilli PK, et al. Mental Health Status among the South Indian Pharmacy Students during Covid-19 Pandemic Quarantine Period: A Cross-Sectional Study. medRxiv. 2020: 2020.2005.2008.20093708. https://doi.org/10. 1101/2020.05.08.20093708.

11. Gruttadaro D and Crudo D. College Students Speak: A Survey on Mental Health. National Alliance on Mental Health. 2012.

12. Emmanuel L. Prevalence and Correlates of Depression, Anxiety and Academic Stress among Science Students in Oduduwa University, Ile- Ife, Nigeria. Texila International Journal of Public Health 2016; 4: 1-11. http://doi.org/10.21522/ TIJPH.2013.04.03.Art001.
13. Cao W, Fang Z, Hou G, et al. The psychological impact of the COVID-19 epidemic on college students in China. Psychiatry Research. 2020; 287: 112934. https://doi.org/10.1016/j.psychres.2020.112934.

14. Zhai $Y$ and Du X. Addressing collegiate mental health amid COVID-19 pandemic. Psychiatry Research. 2020; 288: 113003. https://doi.org/10.1016/j. psychres.2020.113003.

15. Lee RM, Fielding $N$ and Blank $G$. The Internet as a Research Medium: An Editorial Introduction to the Sage Handbook of Online Research Methods. The Sage handbook of online research methods. 2008: 3-20. https://dx.doi.org/10.4135/9780857020055. n1.

16. Lovibond SH, Lovibond PF and Psychology Foundation of $A$. Manual for the depression anxiety stress scales. 1995. http://bit.ly/DASS inst.

17. Eysenbach G. Improving the Quality of Web Surveys: The Checklist for Reporting Results of Internet E-Surveys (CHERRIES). J Med Internet Res. 2004; 6(3): e34. http://doi.org/10.2196/jmir.6.3.e34.

18. Ghimire B. Secondary Education Examination not to be held this year. The Kathmandu Post, June 10 2020; [Link]

19. Neupane P. Violence against women: Along with COVID-19, another crisis is taking place in Nepal. Online khabar. 2020; https://english.onlinekhabar. com/violence-against-women-along-with-covid19-another-crisis-is-taking-place-in-nepal.html

20. Board NE. NEB Releases Assessment Procedure for SEE 2077. Nepalisansar, June 10 2020;

21. Peter G and Sapkota JR. COVID-19: Nepal in Crisis. THE DIPLOMAT. 2020; https://thediplomat. com/2020/06/covid-19-nepal-in-crisis/

22. Wang $C$, Pan $R$, Wan $X$, et al. A longitudinal study on the mental health of general population during the COVID-19 epidemic in China. Brain Behav Immun. 2020; 87: 40-48. https://doi.org/10.1016/j. bbi.2020.04.028.

23. Agency AaN. India: Unable to access online classes, Dalit girl kills herself. Aljazeera, 2020;

24. Zivin K, Eisenberg D, Gollust SE, et al. Persistence of mental health problems and need in a college student population. Journal of affective disorders. 2009; 117(3): 180-185. https://doi.org/10.1016/j. jad.2009.01.001.

25. Pedrelli $P$, Nyer $M$, Yeung $A$, et al. College Students: Mental Health Problems and Treatment Considerations. Academic psychiatry : the journal of the American Association of Directors of Psychiatric Residency Training and the Association for Academic Psychiatry. 2015; 39(5): 503-511. https:// doi.org/10.1007/s40596-014-0205-9.

26. Cao W, Fang Z, Hou G, et al. The psychological 
impact of the COVID-19 epidemic on college students in China. Psychiatry research. 2020; 287: 112934. 10.1016/j.psychres.2020.112934.

27. Restifo $K$ and Bögels $S$. Family processes in the development of youth depression: translating the evidence to treatment. Clinical psychology review. 2009; 29(4): 294-316. https://doi.org/10.1016/j. cpr.2009.02.005.

28. Sander JB and McCarty CA. Youth depression in the family context: familial risk factors and models of treatment. Clin Child Fam Psychol Rev. 2005; 8(3): 203-219. https://doi.org/10.1007/s10567-005-66663.

29. NTA Kathmandu N. Nepal Telecommunications Authority MIS Report. 2019; https://nta.gov.np/en/ mis-reports/

30. Singh DR, Sunuwar DR, Karki K, et al. Knowledge and Perception Towards Universal Safety Precautions During Early Phase of the COVID-19 Outbreak in Nepal. Journal of Community Health. 2020: 1-7. http://doi.org/10.1007/s10900-020-00839-3. 